九州大学学術情報リポジトリ

Kyushu University Institutional Repository

\title{
Aerodynamic Performance Enhancement of Wing Body Micro UAV Employing Blended Winglet Configuration
}

Dominicus Danardono Dwi Prija Tjahjana

Department of Mechanical Engineering, Faculty of Engineering, Universitas Sebelas Maret

Yaningsih, Indri

Department of Mechanical Engineering, Faculty of Engineering, Universitas Sebelas Maret

Billy Yansa Latief Imama

Department of Mechanical Engineering, Faculty of Engineering, Universitas Sebelas Maret

Aditya Rio Prabowo

Department of Mechanical Engineering, Faculty of Engineering, Universitas Sebelas Maret

https://doi.org/10.5109/4742122

出版情報 : Evergreen. 8 (4)，pp.799-811，2021-12. 九州大学グリーンテクノロジー研究教育センター バージョン：

権利関係 : 


\title{
Aerodynamic Performance Enhancement of Wing Body Micro UAV Employing Blended Winglet Configuration
}

\author{
Dominicus Danardono Dwi Prija Tjahjana, *, Indri Yaningsih ${ }^{1, *}$, Billy Yansa \\ Latief Imama ${ }^{1}$, Aditya Rio Prabowo ${ }^{1}$ \\ ${ }^{1}$ Department of Mechanical Engineering, Faculty of Engineering, Universitas Sebelas Maret, \\ Jl. Ir. Sutami 36 A, Surakarta 57126, Indonesia \\ *Author to whom correspondence should be addressed: \\ E-mail: ddanardono@staff.uns.ac.id (D. D. D. P. Tjahjana), indriyaningsih@staff.uns.ac.id (I. Yaningsih)
}

(Received August 3, 2021; Revised October 21, 2021; accepted October 24, 2021).

\begin{abstract}
The wing-body configuration for Micro Unmanned Aircraft Vehicle (UAV) decides their aerodynamics performance which potentially providing benefits for wing design optimization. This challenge leads to the development of future wing body aircraft. The numerical study, utilizing Computational Fluid Dynamics (CFD), is developed in the current work to analyze blended winglet configuration on their performance. Critical parameters combination of taper ratio together with Cant angle were considered. Six wing designs; with no winglet as a baseline, winglet with constant Cant angle of $60^{\circ}$ having $0.3,0.4$, and 0.5 taper ratio values and winglet with a constant taper ratio of 0.3 having $50^{\circ}$ and $70^{\circ}$ Cant angles values, were investigated to observe the vortex distribution and streamline flow behavior of the wingtips. Besides, their effect on lift and drag coefficients and lift to drag ratios were also investigated. Using Reynolds-Averaged-Navier- Stokes (RANS) equation coupled with $k-\omega$ Shear Stress Transport (SST) turbulent model, the current design founds that the best blended-winglet configuration for Micro UAV was the combination of taper ratio of 0.3 and Cant angle of $50^{\circ}$. It enhances the average lift to drag ratio to $9.84 \%$ while reducing the average wingtips vortex to $17 \%$ compared to the baseline (with no winglet).
\end{abstract}

Keywords: blended winglets, Cant angle, taper ratio, aerodynamics performance, micro UAV

\section{Introduction}

\section{Overview}

The aerodynamic performance analysis is important when moving air occurs. As is usual, they are applicable for investigating the difference airfoil design performance for a wind turbine, for example, thin airfoil SD2030 ${ }^{1)}$ and Du96-W-180 wind turbine airfoil ${ }^{2}$. It is also applicable in aircraft applications fields for Unmanned Aerial Vehicles $(\mathrm{UAV})^{3}$.

The increasing demand for UAV or Unmanned Aircraft Systems (UAS) with various mission types opens the wide possibility for an aerodynamics improvement. The numerical simulation using Computational Fluid Dynamics (CFD) can be one of the tools which could provide a robust aerodynamics performance analysis ${ }^{4}$. Nonetheless, the improvement could be very tricky with the optimization procedure and sizing technique ${ }^{5), 6)}$. The overall UAV performance depends on their geometry, systems, and environmental factors ${ }^{7}$. Among the full architecture of aircraft design, the wing-body configuration was the most attractive study in performing the performance optimization. The interaction parameters of the wing-body structure decide their aerodynamic characteristics. The aerodynamics forces over the wing enduring two essential sources of pressure distribution and shear stress ${ }^{8}$. The lifting force drove the wing occurs due to the pressure difference of the lower and upper surface. Therefore, the wing design must offer sufficient lift force to ensure the aircraft can fly with it. Besides the lift force, the drag force and nose-pitching moment must be considered when designing the wing-body. The optimization mostly has been done with maximizing the lift force while reducing the drag force pitching moment. Several wing parameters for UAV through structure and materials ${ }^{9)}$ and wing morphology ${ }^{10)}$ play an essential role in aerodynamics characteristics.

Panagiotou and Yakinthos ${ }^{11)}$ provided a guideline for the aerodynamic performance optimization for fixed-wing UAV. The complete study for UAV operating under a lowspeed subsonic regime was made by providing the effect of UAV configuration on the total drag budget with various angles of attack. They found that the winglet configurations would offer a potential benefit for enhancing the aerodynamics performance. The winglet technology revels in satisfactory readiness level. 
Therefore, the current study focused on modifying wing morphology by adding a blended winglet on the wingbody. A winglet is the adjunction of an aerodynamic device on the wingtip to gain the aircraft's ability to reduce the induced drag. Winglet acts to minimize the vortex size of the wingtip by shifting the vortex. When the winglet properly designs for an aircraft, it could increase the aircraft wing's effectiveness aspect ratio without remarkable total drag and structural load. The following review explained the wing parameter design and its effect on the aerodynamics performance.

The blended-wing-body design has been implemented into civil aircraft by Chen et al. ${ }^{12}$. The impact of mean aerodynamic chord and wetted aspect ratio were investigated to evaluate the stability, control, and lowspeed performance. They found that the high mean aerodynamics chord followed by a high wetted aspect ratio offers the blended-wing-body aircraft's highest efficiency. Boutemedjet ${ }^{13)}$ developed an optimization of UAV aerodynamic design using a genetic algorithm and artificial neural network (ANN). The UAV wing, fuselage design, and empennage were evaluated for the lift, drag, and pitch moment coefficients. The design variables for the wing configuration were aspect ratio, wing loading, wing taper ratio, and wingtip twist angle. Within their study, they also observed the winglet contribution on UAV. The lift coefficient was increased as compared to the wing with no winglet. The additional winglet could reduce the tip vortices effect while adding the lifting surface. Besides, the high taper ratio was able to provide a high lift coefficient. Panagiotou et al. ${ }^{14)}$ developed a conceptual design for the blended wing body of MALE UAV. The winglet utilization reveals $10 \%$ lighter in weight which would be beneficial for lowering fuel consumption and total weight reduction. The improvement of winglet control surface effectiveness was numerically investigated by Bruderlin et al. ${ }^{15)}$. The vortex generator configuration was evaluated to assess the aerodynamics characteristics of the winglet. The vortex generator's presence is expected to increase the control surface's effectiveness at high deflection angles. The vortex generator was able to redirect the flow and increase the lift. Guerrero et al. ${ }^{16)}$ investigated the effect of cant angle and sweep angle of the winglets on aircraft performance. Cant angle adjustment would improve the performance. The blended winglet design can be categorized as a unique design since the wing intersection has no sharp edge but has a smooth curve. Hence, the benefit of using the winglet for UAV that even though giving a slight improvement to the performance of UAV but it might allow to improve the range and has a long duration of time in flight. The research of the modification of wing configuration to enhance the aerodynamics performance was also conducted by the researcher to investigate the parameter details that affected the winglet performance. It was affected by the wing reference ${ }^{17)}$, wing structure ${ }^{18)}$, crosssection $^{19)}$, aspect ratio $^{20)}$, taper ratio $^{21)}$, twist angle ${ }^{22)}$, sweep angle ${ }^{23)}$, span $^{24)}$, number of wings ${ }^{25)}$ and other wing accessories. Considering the literature study, the current study's motivation is to evaluate mutual interaction between taper and Cant angles in aerodynamics performance improvement of Micro UAV.

\section{Novel Configuration}

Micro UAV is one of the UAV classifications, which was based on mean take-off weight (MTOW). The Micro UAV has a characteristic of weight less than $5 \mathrm{~kg}$, range flight distance no more than $10 \mathrm{~km}$, flight height less than $250 \mathrm{~m}$, and endurance less than 1 hour. The available information and technology regarding the unmanned vehicle encourage UAVs to apply for civilian purposes to facilitate work ${ }^{26)}$. The novelty of the current study is judged by considering the Micro UAV characteristics, that is, developing the configuration of a blended winglet (configuring the taper ratio and Cant angle) for reducing the air resistance. The main purpose is to investigate the interaction between the taper ratio and Cant angle to propose the optimized design configuration that could achieve high aerodynamics performance. The design process phase began with the initial layout of a wing with no winglet (baseline). The first comparison was between the wing with no winglet as a baseline and the wing with a blended winglet with three different taper ratios of 0.3 , 0.4 , and 0.5 while maintaining the constant cant angle of $60^{\circ}$. The improved layout has been constructed based on the initial results. Once the taper ratio configuration is decided, the winglet configuration with the different cant angles of $50^{\circ}$ and $70^{\circ}$ will be evaluated to determine the optimum combination of the wing geometry and specified aerodynamics requirements. The Computational Fluid Dynamics (CFD) was utilized to evaluate the flow field characteristics of airflow pattern, vortex structure of the wingtips, lift and drag force behavior.

\section{Methodology}

The detail of the design methodology is presented in Fig. 1. The optimization is designed by improving the layout of the wing. First, as the baseline, the wing with no winglet was evaluated for its aerodynamics performance, including the lift-drag behavior and the wingtips airflow pattern and vortex structure characteristics. Once the wing's performance with no winglet was revealed, the optimization began with the modification of the wing by adding the winglet called blended winglet. The improved layout was done using the blended winglet with three different taper ratios of $0.3,0.4$, and 0.5 while maintaining the constant Cant angle of $60^{\circ}$. After the taper ratio was decided, the modification of the Cant angle was proposed in the current study. It was $50^{\circ}$ and $70^{\circ}$. The optimization method of the study was done by combining two parameters to get the highest aerodynamics performance yet keep the constraint of the mission requirement for micro-UAV to meet the specification of flight and 
structure requirements as shown in Table 1.

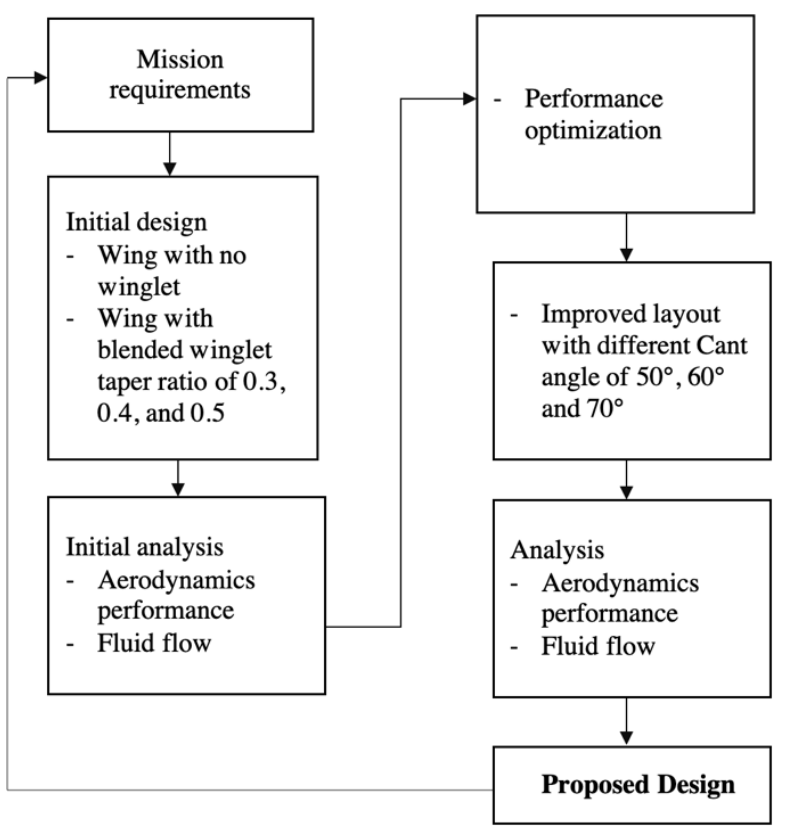

Figure 1. Design methodology.

Table 1 shows the mission requirement of the Micro UAV used in the current study.

Table 1. Mission requirement of Micro UAV

\begin{tabular}{ll}
\hline Specifications & Values \\
\hline Flight \& structural requirements & \\
Minimum Endurance & $1 \mathrm{hour}$ \\
Minimum Flight distance & $30 \mathrm{~km}$ \\
Minimum velocity & $20 \mathrm{~km} / \mathrm{h}$ \\
Cruise velocity & $80 \mathrm{~km} / \mathrm{h}$ \\
Max. Velocity & $100 \mathrm{~km} / \mathrm{h}$ \\
Payload weight & $1.5 \mathrm{~kg}$ \\
MTOW & $3.5 \mathrm{~kg}$ \\
Wing load & $7.79 \mathrm{~kg} / \mathrm{m}$ \\
\end{tabular}

The wing with no winglet and wing with blended winglet having taper ratio of $0.3,0.4$, and 0.5 was examined as the initial design. Preliminary analysis was evaluated through their aerodynamics performance and fluid flow behaviors. After obtaining the best performance from the initial design, the Micro UAV optimization performance was then followed by improving the blended winglet layout with a Cant angle of $50^{\circ}, 60^{\circ}$, and $70^{\circ}$. The analysis of the aerodynamics performance was performed to reveal the best combination of the parameter design. It was intended to achieve the highest performance of the wing structure. Hence, it will be able to fulfill the requirement of the mission. The details of the design and steps for the optimization will be explained later in the following section. The details of the design and steps for the optimization will be explained later on in the following section.

\subsection{Geometric Model Design}

The wing configuration will determine the wing area. Thus, the airfoil selection should meet with the lift coefficient covering the mean take-off weight (MTOW) with a minimum drag coefficient. Table 2 presented the geometry of the main wing configuration.

Table 2. Geometry of the main wing configuration.

\begin{tabular}{ll}
\hline Parameters & Values \\
\hline Chord Tip $\left(C_{T}\right)$ & $0.2 \mathrm{~m}$ \\
Chord Root $\left(C_{R}\right)$ & 0.33 \\
Wing area $(S)$ & $0.449 \mathrm{~m}^{2}$ \\
Wingspan $(b)$ & $1.8 \mathrm{~m}$ \\
Aspect ratio $(\mathrm{AR})$ & 7.22 \\
Taper ratio $(\lambda)$ & 0.61 \\
Incidence angle & $4^{\circ}$ \\
Sweep angle $(\Lambda)$ & $6.86^{\circ}$ \\
Twist angle & $0^{\circ}$ \\
\hline
\end{tabular}

The NACA 2411 airfoil was utilized to generate the main wing design to ensure the airfoil having sufficient lifting force. The results corresponding to NACA 2411 revealed that the wing was expected to give an average lift coefficient of 0.52 within the range attack angle of $0^{\circ}$ to $4^{\circ}$. Moreover, the NACA 2411 airfoil was considered to work within attack angle of $0^{\circ}-10^{\circ}$, since after attack angle of $10^{\circ}$, the NACA 2411 airfoil was experiencing stall. The current study for the design optimization only consists of a wing section without the fuselage and tail section ${ }^{27)}$. This method is aiming to avoid the lift produced by the tail and the fuselage ${ }^{8}$. Figure 2 shows six different layout of wing configurations. 


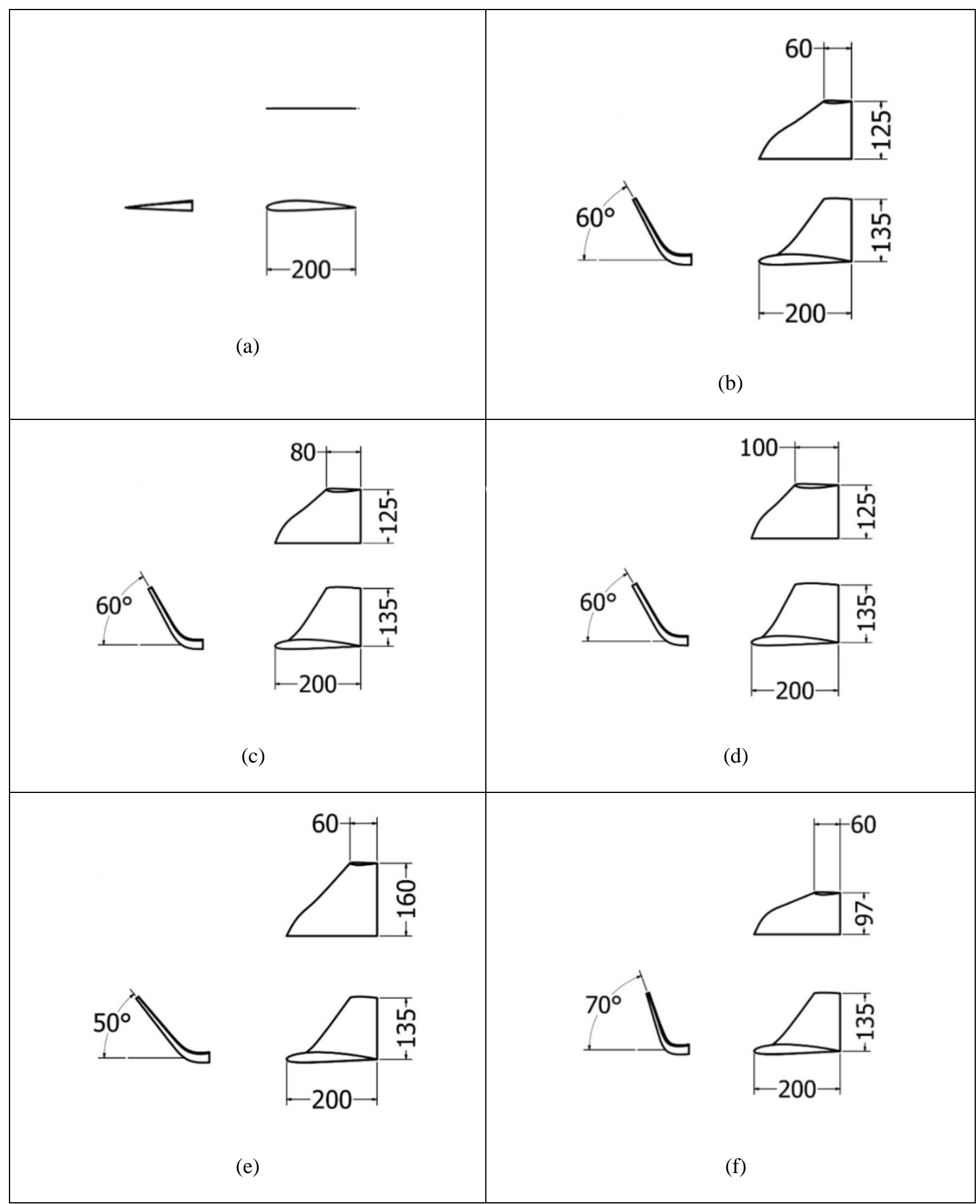

Figure 2. Wing configurations; (a) with no winglet, blended winglet with taper ratio of (b) 0.3 , (c) 0.4 , (d) 0.5 , and blended winglet with Cant angle of (e) $50^{\circ}$, (f) $70^{\circ}$

\subsection{Mesh Generation}

The numerical analysis results and computational time depend on the quality of the chosen computational method. To get an accurate result, the computational network must be carefully developed since it determines the amount of convergence. In the current study, the meshing method was unstructured meshing with mesh topology, mostly dominated by the tetrahedron. It has also been furnished with hybrid grid meshing with hexahedron meshing, particularly in the wing surface. The unstructured meshing is more suitable for wing airfoil and blended winglet since the structure was mostly in the curve shape ${ }^{28)}$. To improve 
the mesh quality, mesh treatment using body sizing with the "body of influence" method; face sizing, especially at leading-edge and trailing-edge, and the inflation layer along the wing surface was applied, which supposed to capture the viscous effect and vortex phenomenon in the winglet or wingtip. Figure 3 shows the mesh treatment for the wing surface.

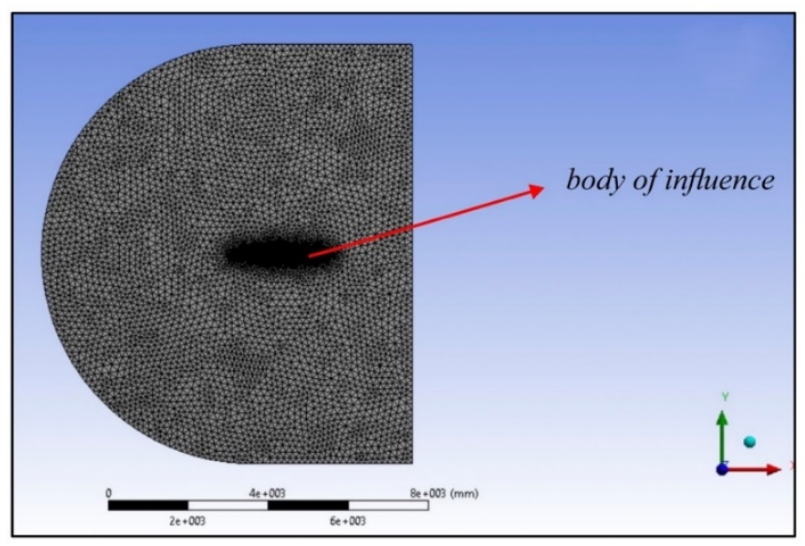

(a)

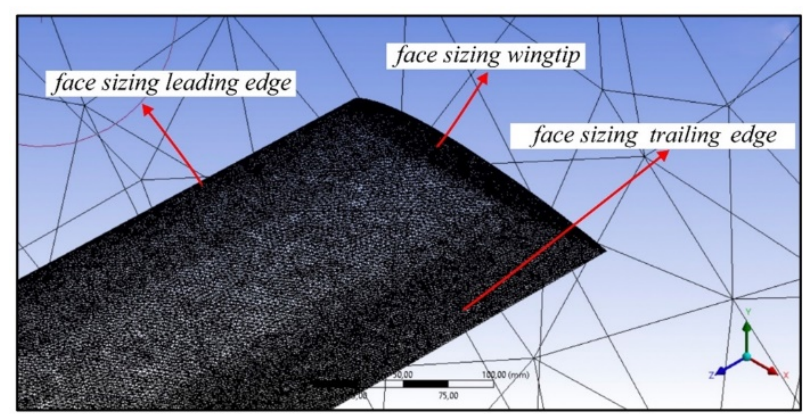

(b)

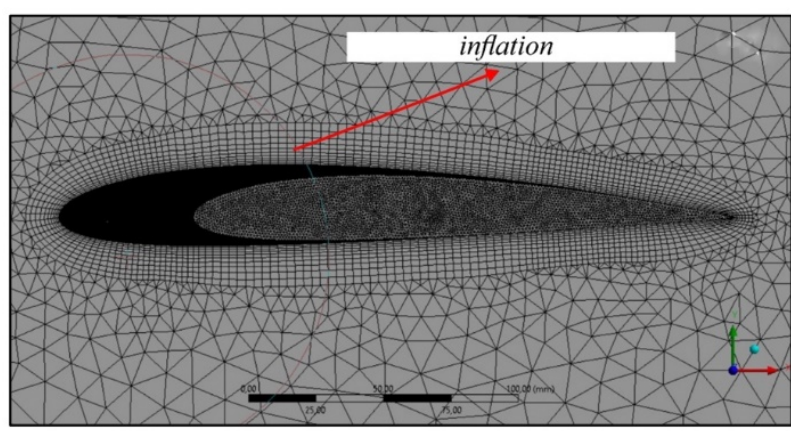

(c)

Figure 3. Wing surface mesh treatment; (a) body of influence method, (b) face sizing, (c) inflation.

Figure 3 (a) depicts the "body of influence" method. It was intended to provide a dense mesh near the wing surface. The face sizing on the wing surface was depicted in Fig. 3 (b). The leading edge, trailing edge, and wingtip were treated with the face sizing since it significantly affected the drag and lift force on the wing's surface. Meanwhile, the mesh treatment using inflation also was utilized in the current study, as shown in Fig. 3 (c). The inflation mesh treatment could visualize the boundary layer and velocity distribution of the fluid flow near the wing surface.

\subsection{Governing Equation}

The air flow was assumed as an external and steady flow, incompressible, and isothermal to simplify the evaluation. Considering the flow as a dynamic flow, the solver was governed by Navier Stokes Equations. It denotes the fundamental principle of mass (continuity), momentum, and energy conservation. It is, however, the energy conservation was ignored due to the isothermal assumption. Based on the assumption, the solution was determined by Reynolds-Averaged Navier Stoke (RANS) equation with the pressure-base method. The conservation of mass and momentum can be written as follows:

Conservation of mass (continuity; steady flow and incompressible flow):

$$
\frac{\partial u}{\partial x}+\frac{\partial v}{\partial y}+\frac{\partial w}{\partial z}=0
$$

Conservation of momentum (Navier-Stokes; steady flow and incompressible flow):

$$
\begin{aligned}
& u \frac{\partial u}{\partial x}+v \frac{\partial v}{\partial y}+w \frac{\partial w}{\partial z}=-\frac{1}{\rho} \frac{\partial p}{\partial x}+v\left(\frac{\partial^{2} u}{\partial x^{2}}+\frac{\partial^{2} u}{\partial y^{2}}+\frac{\partial^{2} u}{\partial z^{2}}\right) \\
& u \frac{\partial u}{\partial x}+v \frac{\partial v}{\partial y}+w \frac{\partial w}{\partial z}=-\frac{1}{\rho} \frac{\partial p}{\partial y}+v\left(\frac{\partial^{2} v}{\partial x^{2}}+\frac{\partial^{2} v}{\partial y^{2}}+\frac{\partial^{2} v}{\partial z^{2}}\right) \\
& u \frac{\partial u}{\partial x}+v \frac{\partial v}{\partial y}+w \frac{\partial w}{\partial z}=-\frac{1}{\rho} \frac{\partial p}{\partial z}+v\left(\frac{\partial^{2} w}{\partial x^{2}}+\frac{\partial^{2} w}{\partial y^{2}}+\frac{\partial^{2} w}{\partial z^{2}}\right)
\end{aligned}
$$

where $\rho$ represents the fluid density, $u, v$, and $w$ determines the velocity for components $x, y$ and $z$, while represents the static pressure.

The prediction of turbulent kinetic energy, $k$, and specific rate dissipation, $\omega$, for separated flow over the wing configurations was estimated by the $k$ - $\omega$ Shear Stress Transport (SST) model ${ }^{29}$ ). This model gives the same trend with experimental data, particularly when having a low attack angle ${ }^{30}$. The RANS equation, then added by these two-following equations:

Turbulence kinetic energy:

$$
\frac{\partial(\rho k)}{\partial t}+\frac{\partial\left(\rho u_{j} k\right)}{\partial x_{j}}=P-\beta^{*} \rho \omega k+\frac{\partial}{\partial x_{j}}\left[\left(\mu+\sigma_{k} \mu_{t}\right) \frac{\partial k}{\partial x_{j}}\right]
$$

Specific dissipation rate:

$$
\begin{aligned}
\frac{\partial(\rho \omega)}{\partial t}+\frac{\partial\left(\rho u_{j} \omega\right)}{\partial x_{j}}=\frac{\gamma}{u_{t}} P-\beta \rho \omega^{2}+ & \frac{\partial}{\partial x_{j}}\left[\left(\mu+\sigma_{\omega} \mu_{t}\right) \frac{\partial \omega}{\partial x_{j}}\right]+ \\
& 2\left(1-F_{1}\right) \sigma_{\omega 2} \frac{1}{\omega} \frac{\partial k}{\partial x_{i}} \frac{\partial \omega}{\partial x_{i}}
\end{aligned}
$$

where $\beta, \gamma, \sigma_{k}$, and $\sigma_{\omega}$ represent the model constant.

\subsection{Boundary Conditions}

The boundary condition of the blended winglet configuration was illustrated in Fig. 4. 


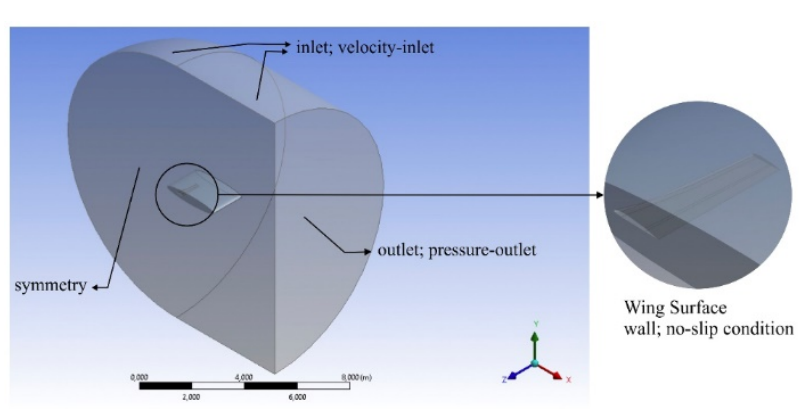

Figure 4. Boundary conditions.

The inlet was set as velocity inlet with a uniform velocity of $40 \mathrm{~m} / \mathrm{s}$, while the outlet was decided as pressure-outlet. The turbulent inlet intensity was in the value of $5 \%$, considering that the UAV will operate at a low altitude (150 AGL). The wing surface was considered as stationary wall with the no-slip condition. The no-slip condition consideration was based on the law of the wall to have velocity distribution due to the shear stress on the inflation layer along the wing surface ${ }^{31)}$.

\subsection{Grid Independence Test and Validation}

The grid independence test has been made to evaluate the resolution and mass quality of the wing surface. The grid independence test has been implemented to the wing geometry with NACA 2412 airfoil owning $1.5 \mathrm{~m}$ of wing length. The validation was done by comparing the lift $\left(C_{L}\right)$ and drag coefficient $\left(C_{D}\right)$ values under the attack of $4^{\circ}$ from Narayan and John ${ }^{27)}$. The grid independence results were provided in Fig. 5.

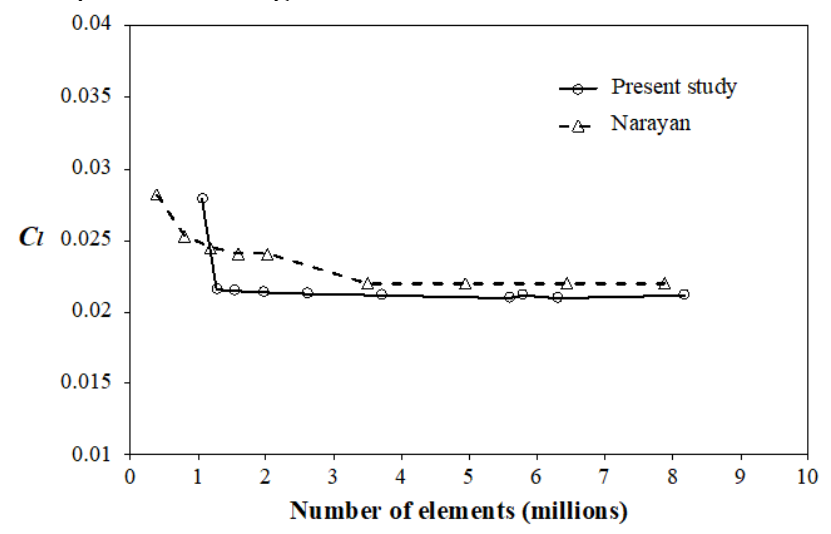

Figure 5. The grid independency test results.

As shown in Fig. 5, the mesh elements number from 6 to 7 million revealed a small discrepancy with Narayan and $\mathrm{John}^{27)}$. Therefore, to reduce the computational time, the mesh with the total number of cells of 6 million has been implemented for the study. After grid independence test and mesh treatment, the mesh characteristics obtained the average skewness value of 0.23 with an average aspect ratio of 2.4. The mesh quality results can be seen in Table 3.
Table 3. The mesh quality results

\begin{tabular}{llll}
\hline Mesh quality & skewness & $\begin{array}{l}\text { aspect } \\
\text { ratio }\end{array}$ & $\begin{array}{l}\text { orthogonal } \\
\text { quality }\end{array}$ \\
\hline & & & \\
Minimum & $9.95 \times 10^{-5}$ & 1.17 & 0.1 \\
Maximum & 0.9 & 13.1 & 0.99 \\
Average & 0.23 & 2.21 & 0.77 \\
Standard & 0.15 & 0.91 & 0.15 \\
Deviation & & & \\
\hline
\end{tabular}

After conducting the grid independency test, the validation has been done for the wing with no winglet (baseline) and wing with winglet. We found that the $C_{L}$ and $C_{D}$ values discrepancy was not apparent. The highest discrepancy was $4.4 \%$. The validation results can be seen in Table 4.

Table 4. Validation results between current work and Narayan and John'27.

\begin{tabular}{|c|c|c|c|c|c|c|}
\hline \multirow{2}{*}{ Geometry } & \multicolumn{2}{|c|}{$\begin{array}{l}\text { Current } \\
\text { Work }\end{array}$} & \multicolumn{2}{|c|}{$\begin{array}{l}\text { Narayan and } \\
\text { John }^{27}\end{array}$} & \multicolumn{2}{|c|}{ Error (\%) } \\
\hline & $\begin{array}{l}C_{L} \\
\left(4^{\circ}\right)\end{array}$ & $\begin{array}{l}C_{D} \\
\left(4^{\circ}\right)\end{array}$ & $\begin{array}{l}C_{L} \\
\left(4^{\circ}\right)\end{array}$ & $\begin{array}{l}C_{D} \\
\left(4^{\circ}\right) \\
\end{array}$ & $\begin{array}{l}C_{L} \\
\left(4^{\circ}\right)\end{array}$ & $\begin{array}{l}C_{D} \\
\left(4^{\circ}\right)\end{array}$ \\
\hline Baseline & 0.45 & 0.0213 & 0.47 & 0.0220 & $3.8 \%$ & $3.3 \%$ \\
\hline $\begin{array}{l}\text { Blended- } \\
\text { winglet }\end{array}$ & 0.46 & 0.0209 & 0.48 & 0.0217 & $4.4 \%$ & $3.9 \%$ \\
\hline
\end{tabular}

The disagreement of the data values could be occurred because of the differences in the computational fluid domain, the first layer thickness $\left(\mathrm{y}^{+}\right)$, and the fluid properties of density and viscosity.

\section{Results and Discussion}

The aerodynamics performance was evaluated with the lift and drag coefficients. These two important values can be calculated by the following Equations:

Lift Coefficient $\left(C_{L}\right)$ :

$$
C_{L}=\frac{L}{\frac{1}{2} \rho_{\infty} V_{\infty}^{2} S}
$$

Drag Coefficient $\left(C_{D}\right)$ :

$$
C_{D}=\frac{D}{\frac{1}{2} \rho_{\infty} V_{\infty}^{2} S}
$$

where $L, \rho_{\infty}, V_{\infty}, S$, and $D$ symbolize respectively for lift force, fluid density, fluid velocity, planform area, and drag force.

The fluid velocity of the current study was kept constant at $22 \mathrm{~m} / \mathrm{s}$ with the airfoil chord length $c=0.2 \mathrm{~m}$. Hence, the Reynolds number found to be 380,000 which was determined by the following Equation:

$$
R e=\frac{c \cdot V_{\infty}}{v}
$$

Not only from lift and drag coefficient, but the 
performance with blended winglets also has been investigated through the vortex and streamline contour of the wingtip. The details of the performance evaluation are discussed in the following section.

\subsection{Effect of Taper Ratio on Aerodynamics Performance}

The effect of blended winglet design can be attained by analyzing the aerodynamics performance of wing with no winglet (baseline) and wings with blended winglet. As shown in Figs 6. a and b portray the lift and drag coefficient characteristics against AoA for baseline and winglet with a taper ratio $(\lambda)$ of $0.3,0.4$, and 0.5 .

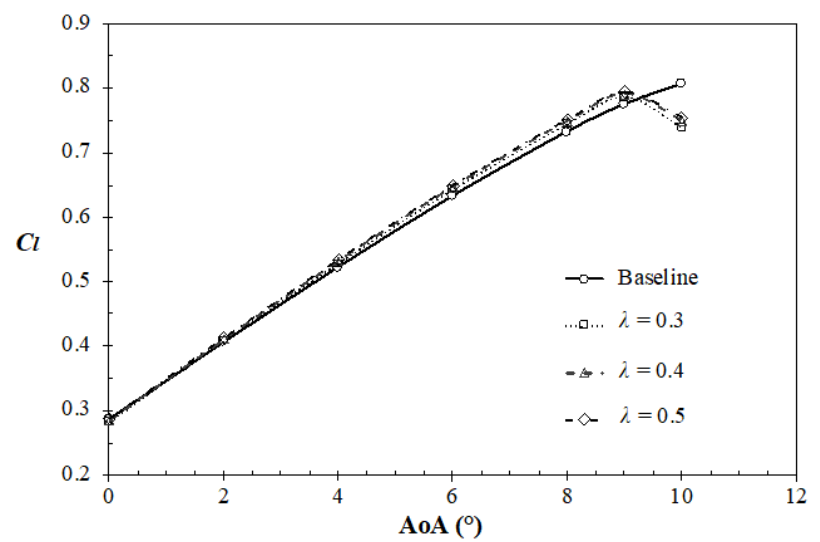

(a)

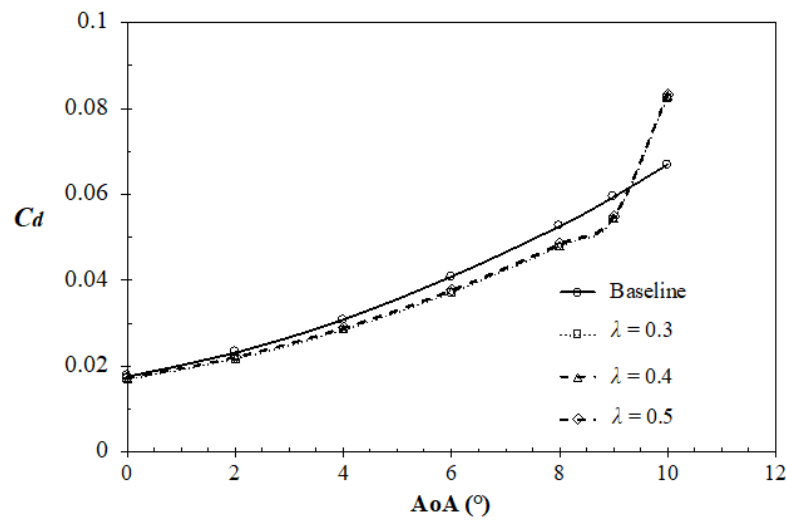

(b)

Figure 6. Lift and drag coefficients behavior against AoA for baseline and winglet with taper ratios variation; (a) lift and (b) drag coefficients.

As the AoA increases, the lift and drag coefficients show an increasing trend until AoA of $9^{\circ}$ for both baseline and wing with winglet. When the AoA further increases to $10^{\circ}$, the blended winglet experienced stall after. It was indicated by the sudden decrease of $C_{l}$ value in Fig. 6a and the sudden increase in $C_{d}$ value in Fig. $6 \mathrm{~b}$. The presence of blended winglets could improve the lift coefficient by around $2 \%$ while reducing the drag coefficient to $10 \%$, as shown in Figs 6. a and b, respectively. The winglet utilization tends to increase the performance by reducing drag forces within high AoA. Yet, their existence could not prevent the wing from a stall in the same condition ${ }^{32}$. Figure 7 displays the trend of lift to drag ratio $\left(C_{L} / C_{D}\right)$ against the AoA.

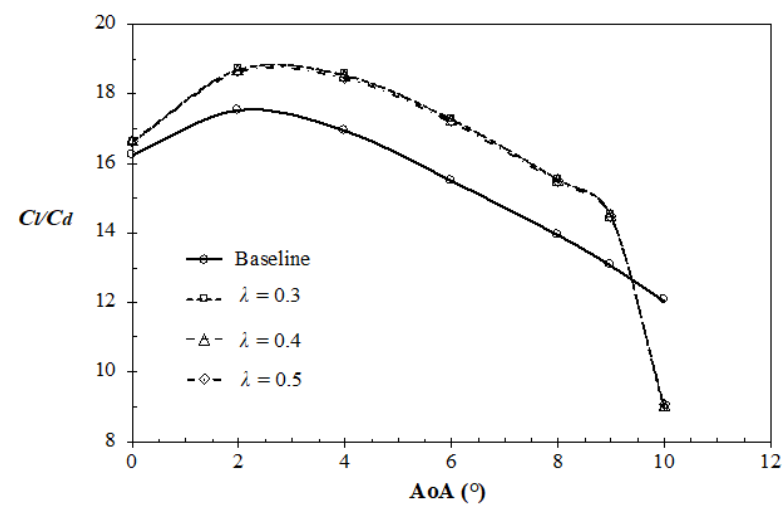

Figure 7. Trends of lift to drag ratio $\left(C_{L} / C_{D}\right)$ of taper ratio configuration against AoA.

The $C_{L} / C_{D}$ determined the effectiveness of the wing to gain the lift force, which generally the drag force will rise with the increment of lift force. The high $C_{L} / C_{D}$ indicates worthy aerodynamics performance. Therefore, using a blended winglet would help improve the $C_{L} / C_{D}$ compared to the baseline. The winglet was capable of reducing the wingtip vortex effect and induced drag component ${ }^{33)}$.

In the taper ratio modification, Figs 6 . $a$ and $b$ indicate no significant effect with the different taper ratio values. The lift to drag ratio also gives a similar trend as depicted in Fig. 7. It occurs because they had almost identical wing aspect ratio. The aspect ratio contributes a more significant effect on the performance. The flow field in the form of the vortex and streamline visualization will be discussed hereafter to deepen the taper ratio's impact.

\subsection{Flow Field of Winglet with Taper Ratio Configuration}

Since the taper ratio effect could not be clearly shown by using the lift and drag coefficient behavior, their effect on flow field will be explained in Fig. 8. 


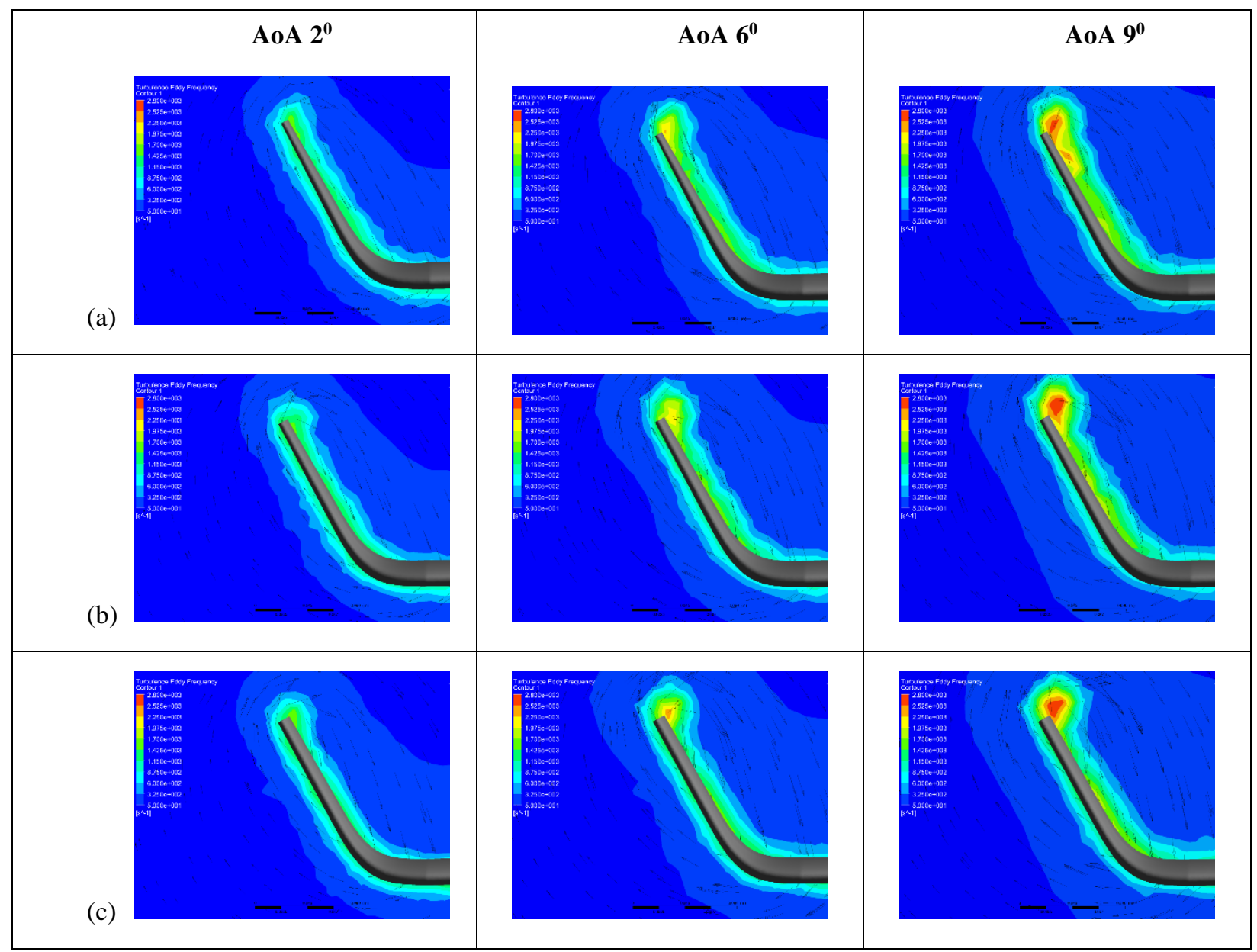

Figure 8. Cross-flow contour of turbulence eddy frequency of winglet with taper ratio of (a) 0.3 , (b) 0.4 , and (c) 0.5 at $x / c=0.2$ and AoA of $2^{\circ}, 6^{\circ}$, and $9^{\circ}$.

Figure 8 provides the crossflow turbulence eddy frequency contour analysis of three different taper ratios with increased AoA from $2^{\circ}$ to $9^{\circ}$. The vortex was intentionally growing up with the increase of AoA. The visualization was selected at $x / c=0.2$, where $x$ was the distance between the contour region and trailing edge and $c$ was the chord root. It can be seen that among three variations of taper ratio, winglet with a taper ratio of 0.3 , Fig. 8 a., presents the smallest turbulent eddy frequency values. Hence, we can say that winglet with a taper ratio of 0.3 offers the best performance with the lowest radial velocity vortex of $2612.28 \mathrm{~s}^{-1}$. It was also supported by the streamline visualization, as shown in Fig. 9.

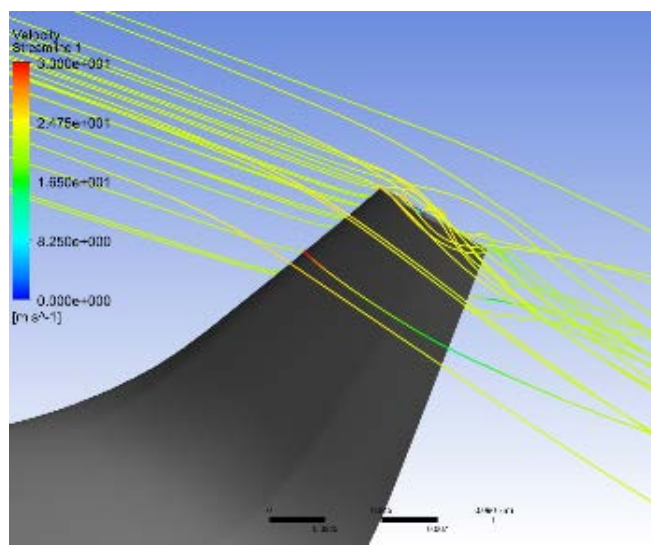

(a) 


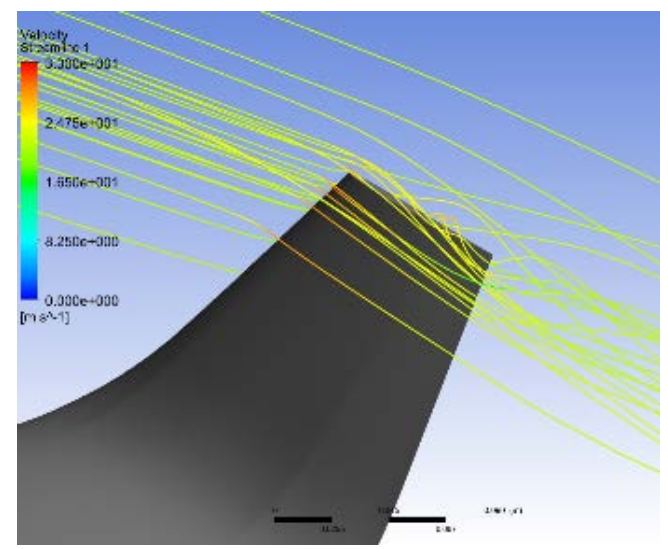

(b)

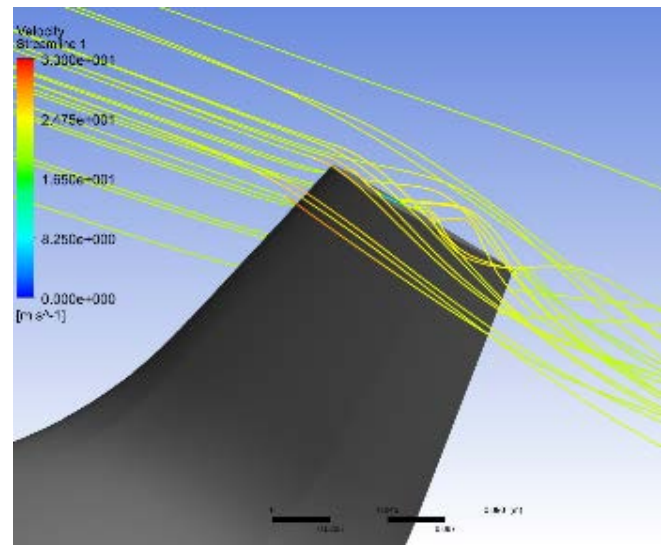

(c)

Figure 9. Streamline visualization of winglet with taper ratio of (a) 0.3 , (b) 0.4 , and (c) 0.5 at $x / c=0.2$ and AoA of $9^{\circ}$.

Figures 9 a, b, and c, showing the streamline visualization of winglets with a taper ratio of $0.3,0.4$, and 0.5 , respectively, at $x / c=0.2$ and AoA of $9^{\circ}$. The winglet with a taper ratio was able to minimize the development of induced drag. When the growth of induced diminished, the formation of the vortex could be reduced. From the results, the winglet with a taper ratio of 0.3 was selected as the basis of layout improvement.

\subsection{Effect of Cant Angle on Aerodynamics Performance}

With selecting the winglet taper ratio of 0.3 , the layout improvement was made by coupling the constant taper ratio with Cant angles of $50^{\circ}, 60^{\circ}$, and $70^{\circ}$. Figures 10 . a and $\mathrm{b}$ present, respectively, for the lift and drag characteristics of winglet with Cant angle of $50^{\circ}, 60^{\circ}$, and $70^{\circ}$.

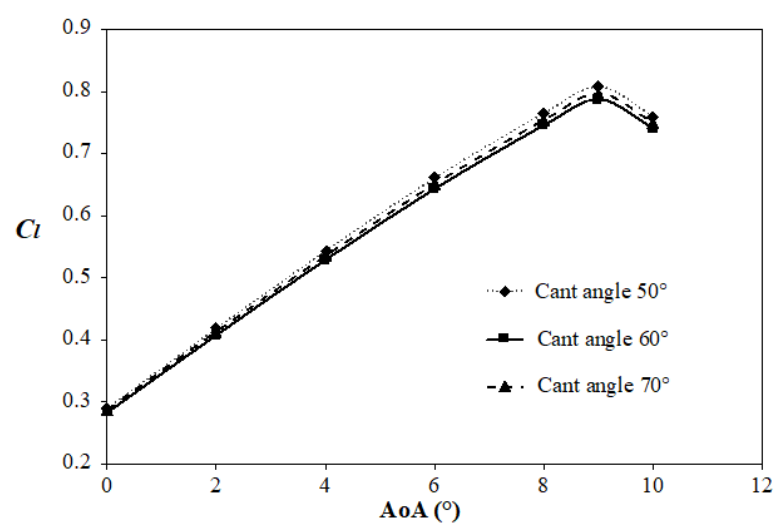

(a)

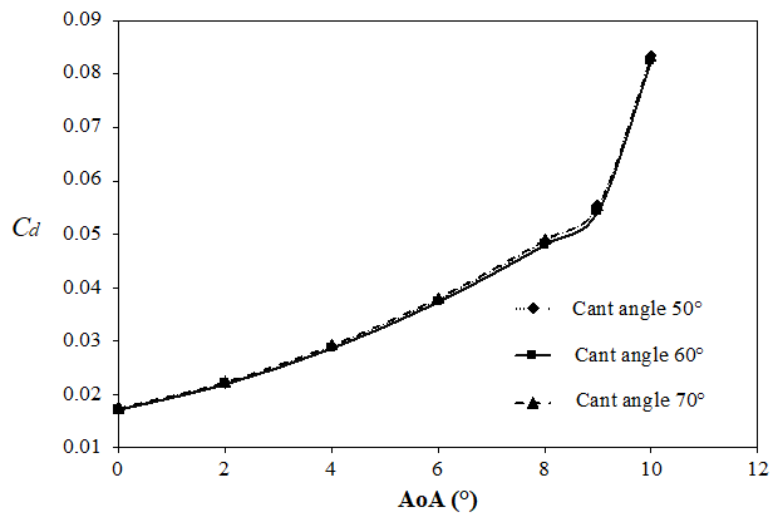

(b)

Figure 10. Lift and drag coefficients behavior against AoA for winglet with Cant angles variation; (a) lift and (b) drag coefficients.

The lift coefficient tends to increase when the AoA raises. The blended winglet with a Cant angle of $50^{\circ}$ performed the highest lift coefficient of 0.81 . Small Cant angle leads to lengthening the wingspan revealed on improving the aspect ratio of wing configuration. The three structures experienced the stall at a similar AoA approaching $10^{\circ}$. It indicates that the Cant angle configuration could not help much to increase the stalling attack angle.

Meanwhile, the drag coefficient of the three Cant angles configuration does not show a considerable discrepancy. However, even it was tiny, the wing with a Cant angle of $50^{\circ}$ having the smallest drag coefficient. This configuration increased the lift coefficient to $10.4 \%$ while reducing the drag coefficient to $9.6 \%$ compared with baseline. Figure 11 presents the lift-to-drag ratio $\left(C_{L} / C_{D}\right)$ of the Cant angle configuration against AoA. 


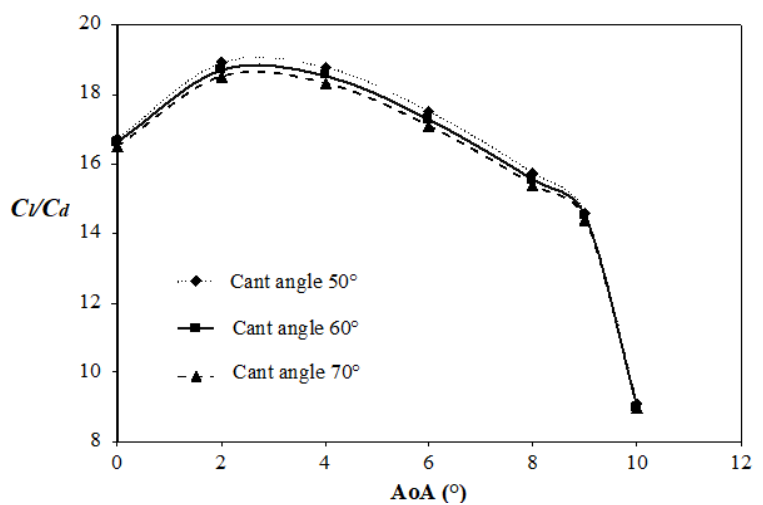

Figure 11. Trends of lift to drag ratio $\left(C_{L} / C_{D}\right)$ of Cant angle configuration againts AoA.
The cant angle of $50^{\circ}$ performing the $C_{L} / C_{D}$ improvement by around $9.84 \%$ up above the baseline. The winglet generates the lift ability of the wing with no increase of induced $\mathrm{drag}^{32)}$.

\subsection{Flow Field of Winglet with Cant Angle Configuration}

The configuration of a blended winglet with different Cant angles reduced the number of vortices on the wingtip, as shown in Fig. 12.

(a)
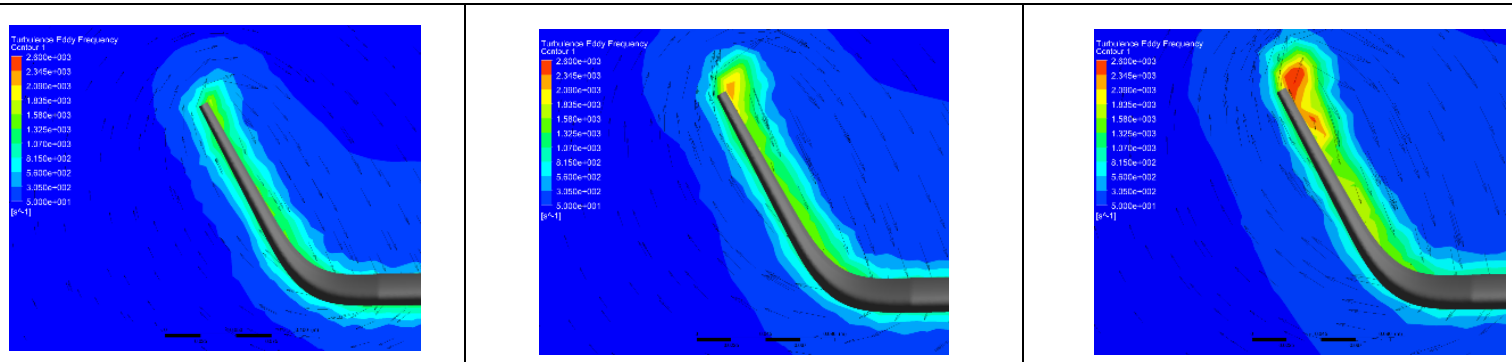

(b)
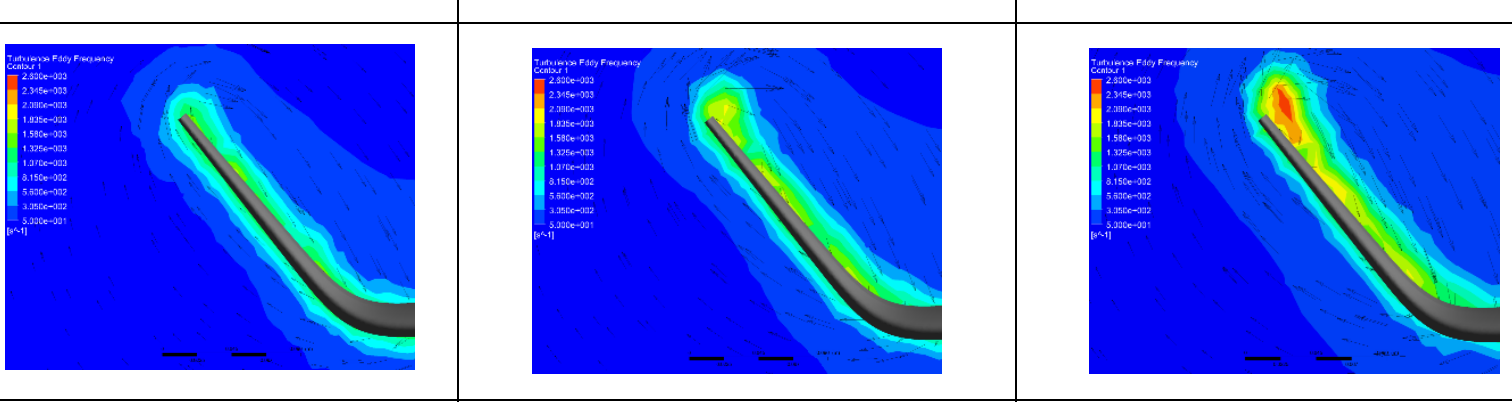

(c)
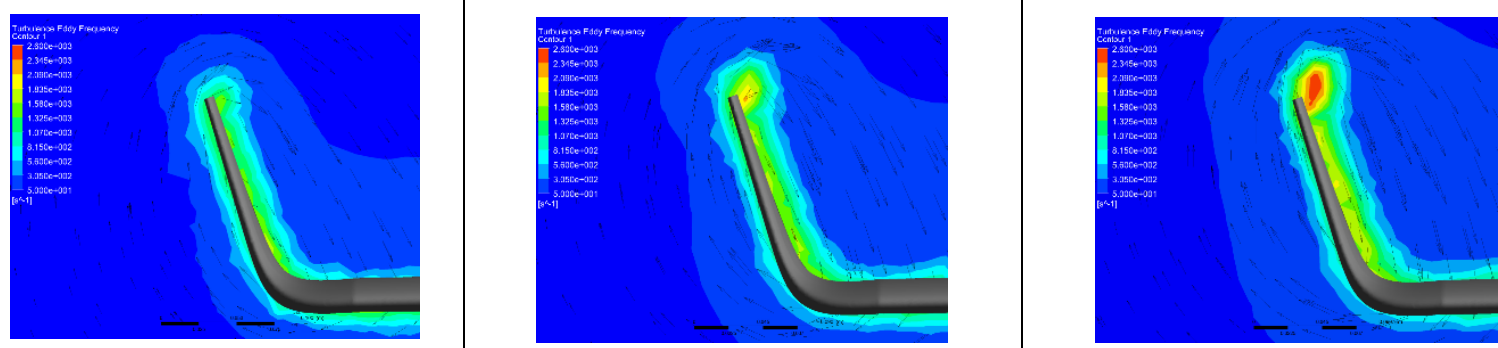

Figure 12. Cross-flow contour of turbulence eddy frequency of winglet with Cant angle of (a) $50^{\circ}$, (b) $60^{\circ}$, and (c) $70^{\circ}$ at $x / c=0.2$ and AoA of $2^{\circ}, 6^{\circ}$; and $9^{\circ}$.

Figures 12 a, b, and c show the cross-flow contour of turbulence eddy frequency of winglet with Cant angle, respectively for $50^{\circ}, 60^{\circ}$, and $70^{\circ}$ at $x / C=0.2$ and AoA of $2^{\circ}, 6^{\circ}$, and $9^{\circ}$. The improvement of AoA magnitude, intensity the vortex development. The vortex radial velocity for Cant angle $50^{\circ}$ established the smallest value with $2581.2 \mathrm{~s}^{-1}$. It reduces the velocity by about $1.2 \%$ and $0.46 \%$ compared to Cant angle $6^{\circ}$ and $7^{\circ}$, respectively. The small reduction indicates that the high attack angle and the Cant angle modification do not contribute to the vortex magnitude. It can also be seen that the winglet utilization affected the cross-flow velocity direction of the flow vector at the wingtip, which moves from high pressure to low pressure was blocked by the shape of the winglet cross-section. Figures 13. a, b, and c depict the streamline visualization of winglets with a Cant angle of $50^{\circ}, 60^{\circ}$, and $70^{\circ}$, respectively. 


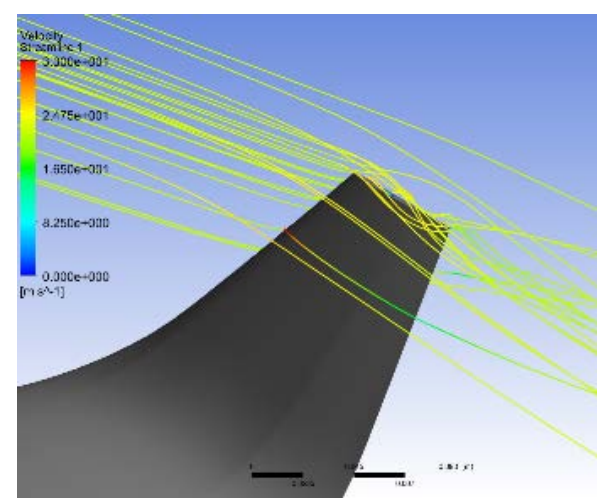

(a)

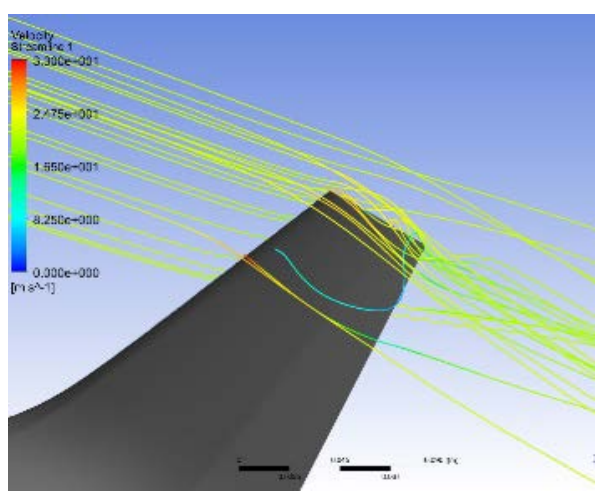

(b)

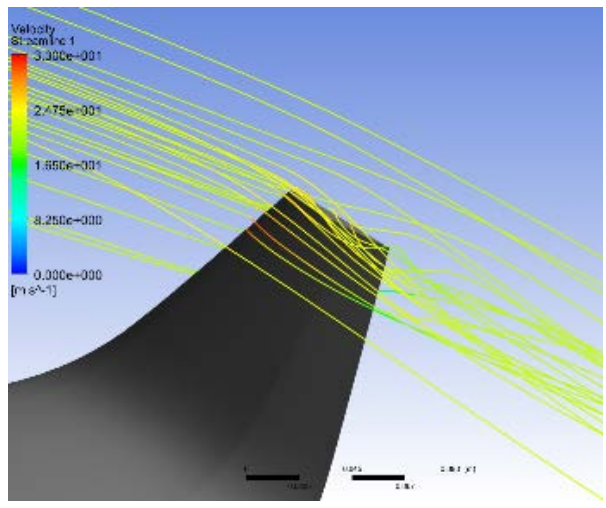

(c)

Figures 13. Streamline visualization of winglet with Cant angle of (a) $50^{\circ}$, (b) $60^{\circ}$, and (c) $70^{\circ}$ at $x / c=0.2$ and AoA of $9^{\circ}$.

All configuration seems to have the similar streamline. However, the Cant angle of $50^{\circ}$ owning smaller vortices at the tip and the flow was mostly dominated by the laminar flow. From the evaluation above, we conclude that the proposed design that offers the highest performance was the wing with a blended winglet configuration of taper ratio 0.3 together with the Cant angle $50^{\circ}$.

\section{Conclusions}

The aerodynamic performance enhancement of wingbody on Micro UAV was numerically studied in the current study. The utilization of blended winglets was investigated to obtain the performance enhancement of the proposed design. The optimization with the combination of key parameters configuration for taper ratio and Cant angle were investigated. Six configurations including the wing with no winglet as a baseline, wing the blended winglets with constant Cant angle of $60^{\circ}$ and taper ratio of $0.3,0.4$, and 0.5 , and wing with blended winglets with a constant taper ratio of 0.3 and Cant angle of $50^{\circ}$ and $70^{\circ}$ were evaluated. The lift and drag coefficients as well as the vortex and streamline analysis were employed to determine the performance. The optimization begins with the comparison of baseline and winglet with taper ratio configuration. The initial layout was then further improved by coupling with the Cant angle arrangement. The presence of blended winglets could improve the lift coefficient by around 2\% while reducing the drag coefficient to $10 \%$. The winglet utilization tends to increase the performance by reducing drag forces within high AoA. The winglet also was capable of reducing the wingtip vortex effect and induced drag component. The winglet with a taper ratio of 0.3 offers the best performance with the lowest radial velocity vortex of $2612.28 \mathrm{~s}^{-1}$. When combining the winglet with taper ratio 0.3 and Cant angle modification, the wing with a Cant angle of $50^{\circ}$ offers the smallest drag coefficient. This configuration increased the lift coefficient to $10.4 \%$ while reducing the drag coefficient to $9.6 \%$ compared with baseline. Therefore, we found that the proposed design that performs the highest performance within the parameter studied was the wing with a blended winglet configuration of taper ratio 0.3 and the Cant angle $50^{\circ}$.

\section{Acknowledgements}

This research is funded by research grant of Hibah Mandatory-PNBP No. 452/UN27.11/PN/2020 and Hibah Penelitian Dasar Unggulan Perguruan Tinggi (PDUPT) 2020, contract number: 112/UN.27.21/HK/2020. The authors thank to the Rector of Universitas Sebelas Maret (UNS) and DRPM Kemenristek/BRIN for financial support.

\section{Nomenclature}

$\begin{array}{ll}C_{L} & \text { lift coefficient (-) } \\ C_{D} & \text { drag coefficient (-) } \\ D & \text { draft force (N) } \\ L & \text { lift force (N) } \\ S & \text { planform area }\left(\mathrm{m}^{2}\right) \\ u & \text { fluid velocity }\left({\left.\mathrm{m} . \mathrm{s}^{-1}\right)}\right.\end{array}$




$$
\begin{array}{ll}
\text { Greek symbols } \\
\rho & \text { fluid density }\left(\mathrm{kg} \cdot \mathrm{m}^{-3}\right) \\
\lambda & \text { taper ratio (-) }
\end{array}
$$

\section{Abbreviation}

AoA

Angle of attack

CFD

Computational Fluid Dynamics

$U A V$

Unmanned Aircraft Vehicle

UAS

Unmanned Aircraft Systems

RANS

Reynolds-Averaged-Navier- Stokes

SST

Shear Stress Transport

\section{References}

1) M. M. Takeyeldein, T. M. Lazim, N. A. R. Nik Mohd, and I. S. Ishak, "Wind Turbine Design Using Thin Airfoil SD2020", EVERGREEN, 6 (2), 144-123 (2019). https://doi.org/10.5109/2321003.

2) A. M. Halawa, B. Elhadidi, and S. Yoshida, "Aerodynamic Performance Enhancement Using Active Flow Control on DU96-W-180 Wind Turbine Airfoil", EVERGREEN, 5 (1), 16-24 (2018). https://doi.org/10.5109/1929723.

3) N. I. Ismail, H. Sharudin, and M. A. Zurriati, "Computational Aerodynamics Study on Neo-Ptero Micro Unmanned Aerial Vehicle", EVERGREEN, 8 (2), 438-444 (2021). https://doi.org/10.5109/4480726.

4) A. M. M. Ismaiel, S. M. Metwalli, B. M. N. Elhadidi, and S. Yoshida, "Fatigue Analysis of an Optimized HWAT Composite Blade", EVERGREEN, 4 (2/3), 16 (2017). https://doi.org/10.5109/1929656.

5) O. M. A. M. Ibrahim and S. Yoshida, "Experimental and Numerical Studies of a Horizontal Axis Wind Turbine Performance over a Steep 2D Hill", EVERGREEN, 5 (3), 12-21 (2018). https://doi.org/10.5109/1957496.

6) S. Kapsalis, P. Panagiotou, and Yakinthos, K. "CFDaided optimization of a tactical Blended-Wing-Body UAV platform using the Taguchi method," Aero. Sci. Tech., 108, 106395 (2021). doi: https://doi.org/10.1016/j.ast.2020.106395.

7) M. A. J. Kuitche, and R. M. Botez, "Modeling novel methodologies for unmanned aerial systems Applications to the UAS-S4 Ehecatl and the UASS45 Bálaam," Chinese J Aeronaut., 32, 1, 58-77 (2019).

Doi: https://doi.org/10.1016/j.cja.2018.10.012.

8) J. D. Anderson, "Aircraft Performance and Design," McGraw-Hill: New York, U.S., 1999.

9) G. D. Goh, S. Agarwala, G. L. Goh, A. Dikshit, S. L. Sing, and W. Y. Yeong, "Additive manufacturing in unmanned aerial vehicles (UAVs): Challenges and potential," Aero. Sci. Tech., 63, 140-151 (2017). http://dx.doi.org/10.1016/j.ast.2016.12.019.

10) O.S. Gabor, A. Koeanschi, R. M. Botez, M. Mamou, and Y. Mebarki, "Numerical simulation and wind tunnel tests investigation and validation of a morphing wing-tip demonstrator aerodynamic performance," Aero. Sci. Tech., 53, 136-153 (2016). http://dx.doi.org/10.1016/j.ast.2017.06.031.

11) P. Panagiotou, and K. Yakinthos, "Aerodynamic efficiency and performance enhancement of fixedwing UAVs," Aero. Sci. Tech., 99, 105575 (2020). https://doi.org/10.1016/j.ast.2019.105575.

12) Z. Chen, M. Zhang, Y. Chen, W. Sang, Z. Tan, D. LI, and B. Zhang, "Assessment on critical technologies for conceptual design of blended-wing-body civil aircraft," Chinese J Aeronaut., 32, 8, 1797-1872 (2019). doi: https://doi.org/10.1016/j.cja.2019.06.006

13) A. Boutemedjet, M. Samardzic, L. Rebhi, Z. Rajic, and T. Mouada, "UAV aerodynamic design involving genetic algorithm and artificial neural network for wing preliminary computation," Aero. Sci. Tech., 84, 464-483 https://doi.org/10.1016/j.ast.2018.09.043.

14) P. Panagiotou, S. Fotiadis-Karras, and K. Yakinthos, "Conceptual design of a Blended Wing Body MALE UAV ," Aero. Sci. Tech., 73, 32-47 (2018). Doi: https://doi.org/10.1016/j.ast.2019.105575.

15) M. Bruderlin, M. Zimmer, N. Hosters, and M. Behr, "Numerical simulation of vortex generators on a winglet control surface," Aero. Sci. Tech., 71, 651660 (2017). Doi: https://doi.org/10.1016/j.ast.2017.10.018.

16) J.E. Guerrero, M. Sanguineti, and K. Wittkowski, "Variable cant angle winglets for improvement of aircraft flight performance," Meccanica., 55, 1917 1947 (2020). Doi: https://doi.org/10.1007/s11012020-01230-1.

17) O. Dündar, M. Bilici, and T. Ünler, "Design and performance analyses of a fixed wing battery VTOL UAV," Eng. Sci. Technol. An Int. J., 23, 1182-1193 (2020).

Doi: https://doi.org/10.1016/j.jestch.2020.02.002.

18) H. Rodrigue, S. Cho, M. Han, B. Bhandari, J. Shim, and S. Ahn, "Effect of twist morphing wing segment on aerodynamic performance of UAV," J. Mech. Sci. Technol., 30, 229-236 (2016). Doi: https://doi.org/10.1007/s12206-015-1226-3.

19) E. Eslami, M. Tadjfar, and S. Najafi, "Aerodynamics performance of Parastoo UAV," Aircr Eng Aerosp Tec., $85 \quad$ (2), 97-103 (2013). Doi: 10.1108/00022661311302706.

20) B.Kirsch, O. Montagnier, E. Bénard, and T. M. Faure, "Tightly coupled aeroelastic model implementation dedicated to fast aeroelastic tailoring optimisation of high aspect ratio composite wing," J Fluids Struct., 94, 102930 (2020). Doi: https://doi.org/10.1016/j.jfluidstructs.2020.102930. 
21) M. Gunasekaran, and R. Mukherjee, "Behaviour of trailing wing(s) in echelon formation due to wing twist and aspect ratio," Aero. Sci. Tech., 63, 294-303 (2017).

Doi: http://dx.doi.org/10.1016/j.ast.2017.01.009.

22) R. K. Kelayeh, and M. H. Djavareshkian, "Aerodynamic investigation of twist angle variation based on wing smarting for a flying wing," Chinese J. Aeronaut., 34 (2), 201-216 (2021), Doi: https://doi.org/10.1016/j.cja.2020.06.022.

23) C. Greatwood, A. Waldock, and T. Richardson, "Perched landing maneuvers with a variable sweep wing UAV," Aero. Sci. Tech., 71, 510-520 (2017). Doi: https://doi.org/10.1016/j.ast.2017.09.034

24) P. D. R. Santos, D. B. Sousa, P. V. Gamboa, and Y. Zhao, "Effect of design parameters on the mass of a variable-span morphing wing based on finite element structural analysis and optimization," Aero. Sci. Tech., 80, 587-603 (2018). Doi: https://doi.org/10.1016/j.ast.2018.07.033.

25) H. Wang, W. Gan, and D. Li, "An investigation of the aerodynamic performance for a propeller-aided liftenhancing double wing configuration," Aero. Sci. Tech., 105, 105991 (2020). Doi: https://doi.org/10.1016/j.ast.2020.105991.

26) K.P. Valavanis, and G.J. Vachtsevanos, "Handbook of Unmanned Aerial Vehicles," Springer Netherlands: Dordrecht, the Netherlands, 2015; pp. 1053-1070.

27) G. Narayan, and B. John, "Effect of winglets induced tip vortex structure on the performance of subsonic wings." Aero. Sci. Tech., 58, 328-340 (2016). doi: https://doi.org/10.1016/j.ast.2016.08.031.

28) Inc ANSYS. ANSYS Fluent release 15 User's Guide. Canonsburg, PA,. 2013.

29) I. Boumrar, and R. Djebali, "Experimental validation of pressure distribution prediction under delta wing apex vortex at high Reynolds numbers." CFD Lett., 11, 92-102 (2019). https://www.akademiabaru.com/submit/index.php/cf dl/article/view/3146.

30) P.W. Chen, C.J. Bai, and W.C. Wang, "Experimental and numerical studies of low aspect ratio wing at critical Reynolds number," Euro. J. Mech., B/Fluids., 59, 161-168 (2016). doi: https://doi.org/10.1016/j.euromechflu.2016.06.005.

31) J. Wells, A. Salem-Said, and S.A. Ragab, "Effects of Turbulence Modeling on RANS Simulations of Tip Vortices," 48th AIAA Aerospace Sciences Meeting Including the New Horizons Forum and Aerospace Exposition:, Florida, U.S., 2010. http://toc.proceedings.com/08053webtoc.pdf.

32) P. Panagiotou, P. Kaparos, and K. Yakinthos, "Winglet design and optimization for a MALE UAV using CFD,” Aerosp. Sci. Technol., vol. 39, pp. 190205, (2014). https://doi.org/10.1016/j.ast.2014.09.006.

33) P. Panagiotou, and K. Yakinthos, "Aerodynamic efficiency and performance enhancement of fixedwing UAVs,” Aerosp. Sci. Technol., vol. 99, 105575, pp. 1-12, https://doi.org/10.1016/j.ast.2019.105575.
(2020). 